\title{
Relationship of Lane Width to Speed for Urban Expressway: A Case Study in Shanghai
}

\author{
Jian Sun ${ }^{\text {a) }}$, Taoning $\mathrm{Li}^{\mathrm{b})}$ \\ School of Transportation Engineering Tongji University, Shanghai 201804, China. \\ a)sunjian@tongji.edu.cn \\ b)1tn_tjseu@163.com
}

\begin{abstract}
In order to mitigate traffic congestions caused by the rapidly increased private car ownership in Shanghai, the transportation agencies implemented several strategies, such as narrowed the lane width to create additional lanes. To investigate the relationship of the lane width to speed, two month of traffic data are collected from 36 sites in the management system of Shanghai expressways. The ANOVA analysis and regression analysis are used to evaluate the effect of average lane width on speed at different levels of service (LOS).
\end{abstract}

Key words: Urban Expressway; Lane Width; Speed; Three-lane Segments; Levels of Service.

\section{INTRODUCTION}

Urban expressway is the skeleton of urban transport system, undertaking a large quantity of urban motorized traffic. Over the past decade, in order to meet the increasing traffic demand, Shanghai expressway has been partly reconstructed to create additional lanes. With the cross-section width remaining the same, the average lane width is narrowed to some extent. Field measurement of sites shows that the maximum lane width is $3.97 \mathrm{~m}$, and the minimum lane width is $2.73 \mathrm{~m}$.

Narrowing the lane widths might have impacts on the safety, capacity, and speed under comparative high level of service (LOS) condition. The effect of lane width on capacity and safety has been analyzed in two previous studies $(1,2)$. In this paper, the relationship of the lane width to the speeds at different levels of service (LOS A-C) is evaluated based on the filed data collected from Shanghai urban expressway.

This paper is organized as follows. A brief review of the literature about the effect of the lane width and the speed is conducted in the following section. The study sites and the data are presented in section 3 . Then, the impact of lane width on speeds for different LOSs (A-C) is described in section 4. In section 5, the effect of cross-sectional factors on speeds for different drivers and speed for each single lane is discussed. The final section then summarizes the findings and offers some suggestion for the designing and management of the urban expressway.

\section{LITERATURE REVIEW}

Studies on the lane width have been done for a long time, mostly investigating the effect of lane width on safety (2) and capacity $(1,3)$, but fewer studies concern the effect on speed. As following, a comprehensive review of previous studies that dealt with the impact of lane width on speed will be presented from the aspects of highway/freeway.

In the HCM2010 (4), average lane width has a direct impact on the FFS for freeways, which is adjusted by lane width, lateral clearance and so on. When the average lane width is less than $3.66 \mathrm{~m}$ but more than $3.35 \mathrm{~m}(11-12 \mathrm{ft})$, FFS needs to be reduced by $3.04 \mathrm{~km} / \mathrm{h}(1.9 \mathrm{mile} / \mathrm{h})$. When the lane width is $3.05-3.55 \mathrm{~m}$, the reduction coefficient is up to $10.56 \mathrm{~km} / \mathrm{h}$. And there is no statement about the lane width less than $3.05 \mathrm{~m}$. 
Leong (5) measured at 31 locations on straight sections of two-lane two-way rural highways during $1963 \sim 1967$. He found that the increase in pavement width, shoulder width and sight distance can increase the FFS. Yagar et al. (6) studied geometric effects on speeds of two-lane highways. They pointed out that the passage of vehicles requires a minimum lane width and any additional width beyond this minimum allows one to drive faster. It was found that the operating speed of a given location is decreased by approximately $5.7 \mathrm{~km} / \mathrm{h}$ for each meter of reduction in lane width in the range from 3.3 to $3.8 \mathrm{~m}$. Alberto (7) presented free-flow speed models that identify factors of mean speed on tangent segments of two-lane rural highways. The model showed that the wider pavement and shoulder can increase the mean speed, and the shoulder has a much greater influence than pavement width.

From the previous studies, it can be found that there is no consistent result about the relationship between the lane width and the speed and there is wide variability between different sites, but the studies generally agree that when the lane width is reduced, the speed of vehicles will be decreased. Most of these studies focused on highways/freeways, few studies about urban expressways. Also, the studies just focused on the FFS or operating speed when the traffic flow is quite small, there are no systematic studies focuses on the relationship of lane width to speeds considering different service levels and different driver types.

\section{THE SITES AND THE DATA}

\section{The Sites}

In order to properly analyze the effect of lane width and avoid the potential confound factors, the candidate sites must meet the following criteria: 1) Basic segment. Not or very little affected by merging, diverging, or weaving traffic flow. 2) Straight and little gradient segment. 3) Similar vehicle composition. 4) Driver population is regular commuters. 5) Posted speed limit: $80 \mathrm{~km} / \mathrm{h}$.

\section{Lane Width Data}

The site investigation was manually surveyed during midnight from 00:30 a.m. to 5:00 a.m. in 2014.Figure 1 shows the distributions of the lane width data for different number of lanes in one direction of Shanghai expressway. Compared with the one-way two-lane and four-lane expressways, the three-lane expressways have the most adequate width data. So in this paper, only the data of three-lane expressway segments are considered, and 36 eligible sites are satisfied based on aforementioned criteria.

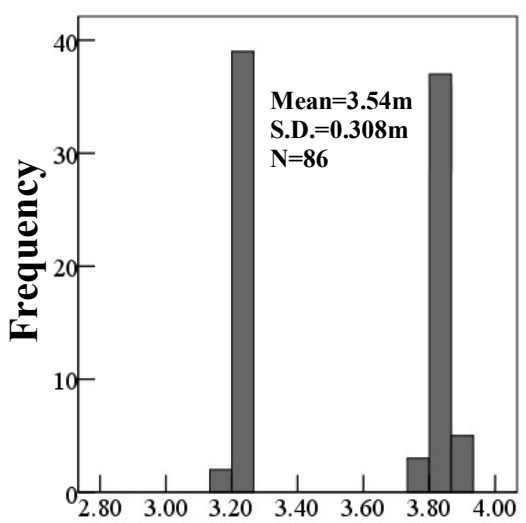

(a)Two-lane

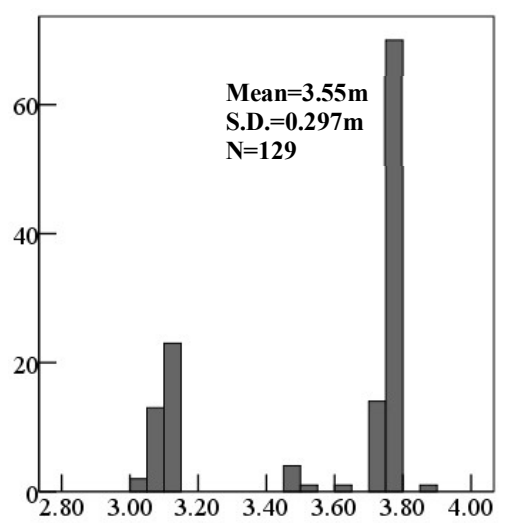

(b) Three-lane

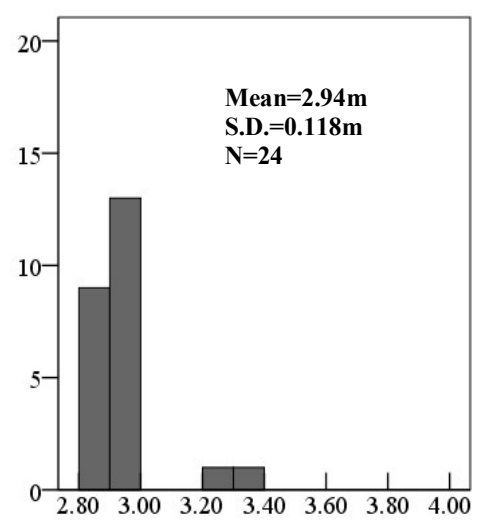

(c) Four-lane

FIG. 1. The distribution of the lane width data in Shanghai expressway 


\title{
EFFECT OF THE LANE WIDTH ON THE SPEED
}

\section{Definition and Classification}

\author{
The Definition of Traffic flow for Speed Comparison
}

The influence of lane width on speed appears more evident with the low traffic flow. Most of the studies only focused on the effect of the lane width on the free-flow speed. Compared with the constant FFS in the HCM 2010, the speed-flow curve in Shanghai shows a parabola relationship (as shown in Figure 2), where the free flow speed only lasts for (LOS A). With the increase of the flow rate, more vehicles will be affected by other vehicles in adjacent lanes and the speed declines. Thus, our analysis includes the comparison of speeds for A-C service levels, which are mentioned as speedLOSA, speedLOSB and speedLOSC (considering the speed is severely affected by traffic flow below LOS D, speeds under LOS D are not included in this study).

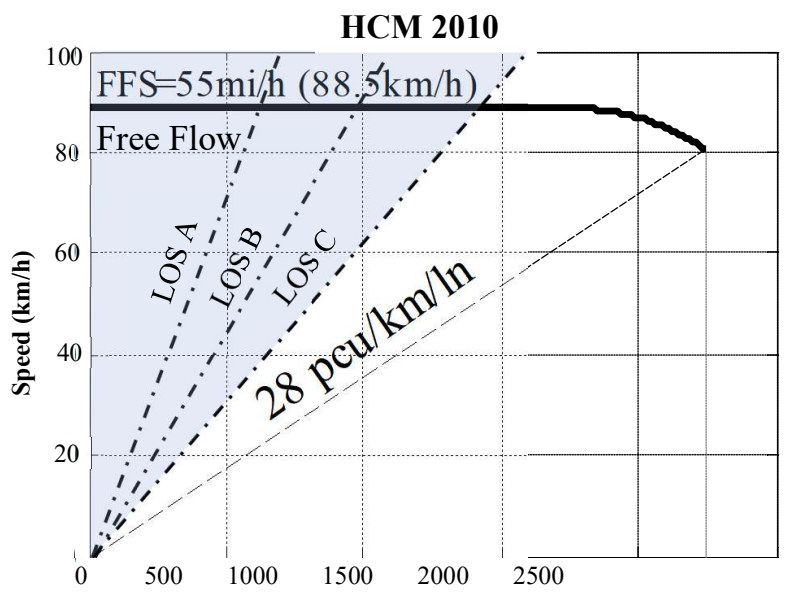

(a) Flow Rate (pcu/h/ln)

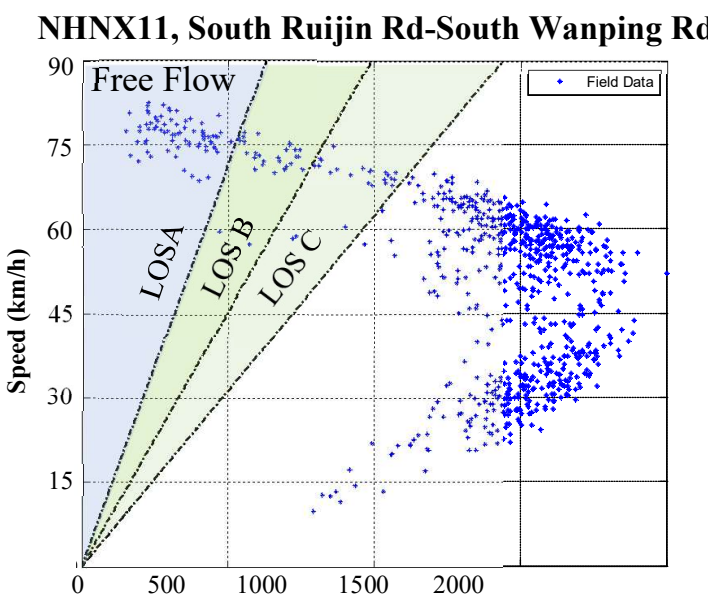

(b) Flow Rate (pcu/h//n)

FIG. 2. Speed-flow curves in HCM 2010 and in Shanghai expressway.

The Classification of Lane Width

Considering the uncontinuity of the width data, the widths are treated as categorical variables rather than as continuous variables. The grouped criteria: 1) Undersize: $<3.25 \mathrm{~m}$. 2) Standard size: $\geq 3.25 \mathrm{~m} \&<3.75 \mathrm{~m}$. 3) Oversize: $\geq 3.75 \mathrm{~m}$. The lateral clearances and standard deviation of lane widths are also divided into three sizes respectively. The categories of lateral clearance (LC): 1) LC1: $<0.15 \mathrm{~m}$. 2) LC2: $\geq 0.15 \mathrm{~m} \mathrm{\&}<0.30 \mathrm{~m}$. 3) LC3: $\geq 0.30 \mathrm{~m} \&<0.45 \mathrm{~m}$. The categories of standard deviation of lane widths (S.D.): 1) SD1: $<0.10 \mathrm{~m} .2)$ SD2: $\geq 0.10 \mathrm{~m} \&<0.20 \mathrm{~m}$. 3) SD3: $\geq 0.20 \mathrm{~m}$.

\section{Regression Analysis}

It is found that the vehicle speeds at one site fit into normal distribution under free flow conditions (8). For each LOS (A-C), the speeds are found to obey the normal distribution. In order to quantify the impact of lane width on speed, regression analysis is also applied. Based on spearman correlation test, right lateral clearance (RLC) and left lateral clearance (LLC) are highly positive relevance. Besides, according to the ANOVA test, the RLC is less attributable than lane width to the change of speeds. Thus, the cross-sectional factors considered in this paper include average lane width (LW), LLC and the standard deviation of lane widths (S.D.). The regression model is shown as:

$$
\text { Speed }_{L o s i}=a+b_{1} L W_{1}+b_{2} L W_{2}+b_{3} L W_{3}+c_{1} L C_{1}+c_{2} L C_{2}+c_{3} L L C_{3}+d_{1} S D_{1}+d_{2} S D_{2}+d_{3} S D_{3}
$$


Where,

Speed $=$ predicted free-flow speed $\mathrm{LW} 1=1$ if lane width is undersize; $=0$ if not; LW3 $=1$ if lane width is oversize; $=0$ if not;

$\mathrm{LLC} 2=1$ if $\mathrm{LLC}$ is LC2; $=0$ if not;

$\mathrm{SD} 1=1$ if $\mathrm{LLC}$ is SD1; $=0$ if not;

$\mathrm{SD} 3=1$ if LLC is SD3; $=0$ if not;
LOS $\mathrm{i}=$ for level of service of $\mathrm{i}(\mathrm{i}=\mathrm{A}, \mathrm{B}, \mathrm{C})$;

LW2 $=1$ if lane width is standard size; $=0$ if not;

$L L C 1=1$ if $L L C$ is $L C 1$; $=0$ if not;

LLC3 $=1$ if $\mathrm{LLC}$ is LC3; =0 if not;

$\mathrm{SD} 2=1$ if $\mathrm{LLC}$ is SD2; $=0$ if not;

$\mathrm{a}, \mathrm{b}, \mathrm{c}, \mathrm{d}=$ regression coefficients;

Table 1 shows the results of regression analysis models. At each LOS, LW2, LLC1 and SD2 are set as the dummy variables whose coefficients equal 0 and are used for comparisons. For example, under LOS A, the effect of the lane width on speedLOSA is expressed through comparison to standard-sized lane (LW2) (i.e., the coefficient of LW2 is zero). The coefficient of LW1 is -4.53 , which means the undersized lane can reduce the speedLOSA by $4.53 \mathrm{~km} / \mathrm{h}$ compared with standard-sized lanes. But its p-value shows that the coefficient of standard-sized lane is not significant. The regression analysis model is statistically significant with R2 about 0.771 .

TABLE 1. Results of Regression Analysis Models

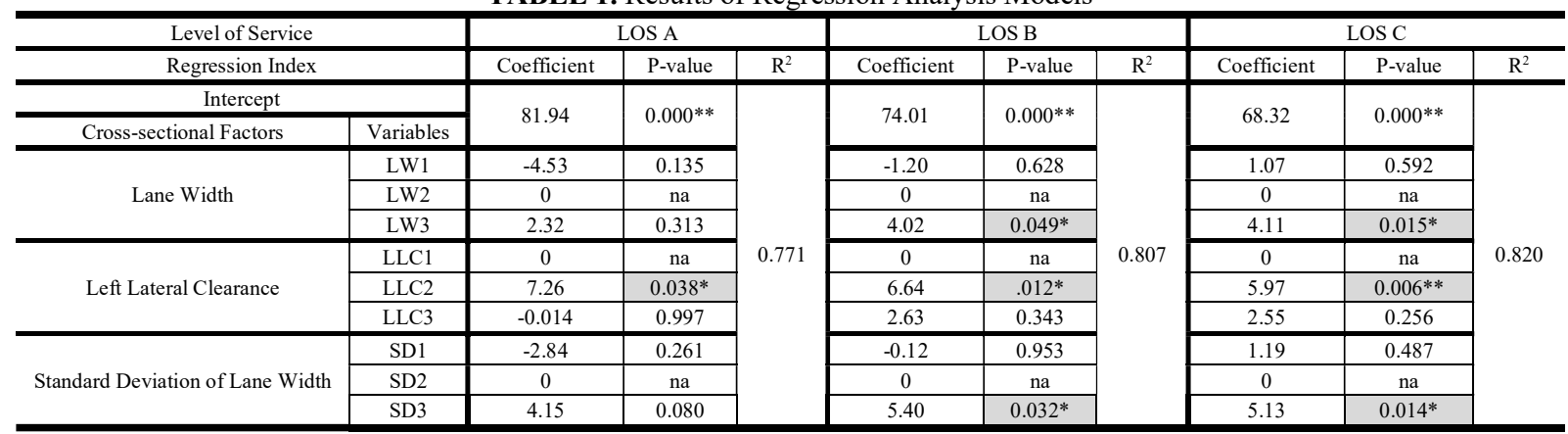

Note: $*, * *=$ the significance is at $0.05,0.01$ level respectively.US $=$ undersized lane $\mathrm{SS}=$ Standard-sized lane, $\mathrm{OS}=$ oversized lane. na $=$ not applicable.

At the $95 \%$ confidence level, from the statistically significant coefficients in the models, at LOS A, speedLOSA may be affected by LLC only; at LOS B and LOS C, the speeds are affected by the wider lane width, LLC and S.D. of lane widths. From the p-values in Table 4, it can also come to the conclusion that with the decline in LOS (from A to $\mathrm{C})$, the effect of average lane width is growing.

The possible reason is that, under very low traffic density (LOS A), when drivers can choose and change their desired lanes freely, the effect of average lane width is not significant. For LOS B and C, with the increase of traffic density, the drivers can feel the pressure from the vehicle at adjacent lanes, the effect of average lane width appears more significant.

\section{THE EFFECT OF LANE WIDTH ON SPEEDS TO DIFFERENT TYPES OF DRIVERS}

Since China is ongoing the rapid motorization process, many drivers are novices in society. Professional drives, skilled drivers and novices may show different driving tendency and desired speed, and they may have different perception to the lane width. In this section, we focus on the effect of lane width on speeds of different kind of drivers. We use different desired speed to characterize the type of drivers. That is, the timid drivers are expected to be slower; the aggressive are expected to be faster and the ordinary are in between.

Since the loop detectors can only provide traffic flow data with a minimum interval of 20 s, we cluster the 20 sinterval data into three types of drivers (i.e. timid, ordinary and aggressive drives) (9), on basis of which we analyze the desired speed distribution and the effect of lane width on speeds of each types of drivers. In accordance with the principle of minimum distance, the data collected are clustered into three groups.

Figure 3 shows the speed cumulative frequency curves of different drivers under free flow Shanghai expressway. We can see the speed variation from one type to another is considerable (about $15 \mathrm{~km} / \mathrm{h}$ ). 


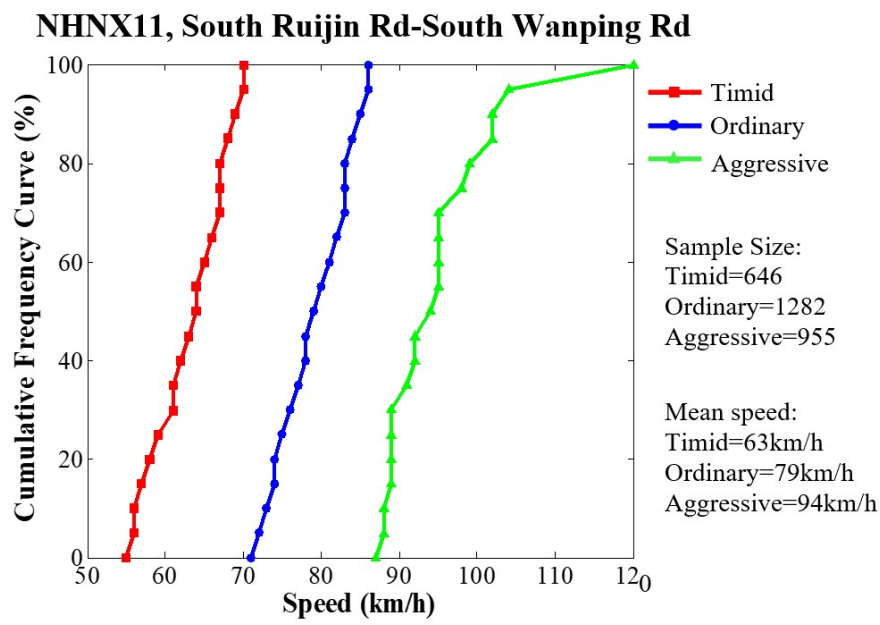

FIG. 3. Speed cumulative frequency curves of different drivers under free flow.

For each kind of drivers, we use multi-factor ANOVA to test the effect of the cross-sectional factors, which include lane width, lateral clearance, S.D. of lane width and lane position (median, center and shoulder lane), on speeds for LOS A-C. Table 2 presents the results of ANOVA test. The p-value tells that for timid drivers, at $95 \%$ confidence level, lane width has a significant influence on speed for all three LOSs. For ordinary drivers, lane width has no significant influence on speedLOSA and speedLOSB, but the influence grows significant when the LOS drops to C. For aggressive drivers, whatever the LOS is, the influence of lane width on their speed is not significant. Thus, the conclusions drawn that the timid drivers are sensitive to lane width, while the aggressive are not, and the ordinary are in between whose speed are only affected by lane width for LOS C.

TABLE 2. Multi-Factor ANOVA Test Result of Different Drivers

\begin{tabular}{|c|c|c|c|c|c|c|c|c|c|}
\hline \multicolumn{10}{|c|}{ Timid drivers } \\
\hline Level of Service & & LOS A & & & LOS B & & & LOS C & \\
\hline Test Factor & F-value & $\mathrm{p}$-value & $\mathrm{R}^{2}$ & F-value & $\mathrm{p}$-value & $\mathrm{R}^{2}$ & F-value & $\mathrm{p}$-value & $\mathrm{R}^{2}$ \\
\hline Lane Width & 5.777 & $0.019^{*}$ & \multirow{5}{*}{0.669} & 5.222 & $0.026^{*}$ & \multirow{5}{*}{0.585} & 9.693 & $0.003 * *$ & \multirow{5}{*}{0.638} \\
\hline LLC & 38.92 & $0.000 * *$ & & 38.035 & $0.000 * *$ & & 42.201 & $0.000 * *$ & \\
\hline RLC & 17.654 & $0.000 * *$ & & 15.225 & $0.000 * *$ & & 14.658 & $0.000 * *$ & \\
\hline S.D. of three lanes & 8.391 & $0.001 * *$ & & 5.212 & $0.008^{* *}$ & & 6.723 & $0.002 * *$ & \\
\hline Lane Position & 28.644 & $0.000 * *$ & & 13.777 & $0.000 * *$ & & 17.3 & $0.000 * *$ & \\
\hline \multicolumn{10}{|c|}{ Ordinary drivers } \\
\hline Level of Service & & LOS A & & & LOS B & & & LOS C & \\
\hline Test Factor & F-value & p-value & $\mathrm{R}^{2}$ & F-value & $\mathrm{p}$-value & $\mathrm{R}^{2}$ & F-value & $\mathrm{p}$-value & $\mathrm{R}^{2}$ \\
\hline Lane Width & 1.908 & 0.172 & \multirow{5}{*}{0.484} & 3.861 & 0.054 & \multirow{5}{*}{0.56} & 7.288 & $0.000 * *$ & \multirow{5}{*}{0.649} \\
\hline LLC & 20.647 & $0.000 * *$ & & 27.903 & $0.000 * *$ & & 39.946 & $0.000^{* *}$ & \\
\hline RLC & 7.411 & $0.008 * *$ & & 10.87 & $0.002 * *$ & & 16.817 & $0.000 * *$ & \\
\hline S.D. of three lanes & 6.081 & $0.004 * *$ & & 6.019 & $0.004 * *$ & & 8.982 & $0.000 * *$ & \\
\hline Lane Position & 5.885 & $0.005 * *$ & & 8.93 & $0.000 * *$ & & 13.24 & $0.000 * *$ & \\
\hline \multicolumn{10}{|c|}{ Aggressive drivers } \\
\hline Level of Service & \multicolumn{3}{|c|}{ LOS A } & \multicolumn{3}{|c|}{ LOS B } & \multicolumn{3}{|c|}{ LOS C } \\
\hline Test Factor & F-value & p-value & $\mathrm{R}^{2}$ & F-value & p-value & $\mathrm{R}^{2}$ & F-value & $\mathrm{p}$-value & $\mathrm{R}^{2}$ \\
\hline Lane Width & 0.133 & 0.717 & \multirow{5}{*}{0.342} & 0.791 & 0.377 & \multirow{5}{*}{0.339} & 3.025 & 0.087 & \multirow{5}{*}{0.477} \\
\hline LLC & 9.245 & $0.000 * *$ & & 6.382 & $0.014^{*}$ & & 8.484 & $0.005 * *$ & \\
\hline RLC & 2.212 & 0.142 & & 1.271 & 0.264 & & 1.788 & 0.186 & \\
\hline S.D. of three lanes & 5.103 & $0.009 * *$ & & 5.063 & $0.009 * *$ & & 8.846 & $0.000 * *$ & \\
\hline Lane Position & 0.729 & 0.486 & & 2.243 & 0.115 & & 4.575 & $0.014^{*}$ & \\
\hline
\end{tabular}

Note: $*, * *=$ the significance is at $0.05,0.01$ level respectively.

Note: cons $=$ constant

It can be an explanation for the findings from section 4 that the overall drivers are insensitive to lane width at LOS A. There are two reasons. For one hand, the timid drivers account for less than $30 \%$ of the entire driver group and the 
majority of which is composed of ordinary and the aggressive drivers which almost show no sensitivities. As a result, the entire group is not sensitive to lane width. For the other hand, there are exist differences in speeds under different lane widths for timid drivers. However, the difference is minor $(<2 \mathrm{~km} / \mathrm{h})$ compared with the speed error of ordinary and aggressive drivers. Consequently, it is difficult for the timid drivers to make a difference to the speed characteristic of the entire driver group at LOS A.

\section{CONCLUSION}

In this study, 36 sites are selected for the investigation of relationship between lane width and speed in Shanghai expressway. The ANOVA analysis and regression analysis are used to evaluate the effect of lane width on speed. Moreover, the effect of cross-sectional factors on speeds for different drivers is also discussed. Main conclusions are as follows:

For LOSA, LLC instead of lane width has a significant effect on the difference of FFSs; For LOSB and C, lane width become the influential factor to speeds, but the LLC and S.D. of lane widths are more attributable than lane width.

From the aspect of different driver types, the timid drivers are sensitive to lane width, while the ordinary and the aggressive drivers are comparatively unresponsive to different lane width.

\section{ACKNOWLEDGMENTS}

The authors would like to thank the Shanghai Science and technology project of international cooperation (16510711400) for supporting this study.

\section{REFERENCES}

1. Zheng, J., J. Sun. and J. Yang. Relationship of Lane Width to Capacity for Urban Expressway. In Transportation Research Record: Journal of the Transportation Research Board. No.15-0465, Transportation Research Board of the National Academies, Washington, D.C., 2015.

2. Wu, L., J. Sun. Relationship of Lane Width to Safety for Urban Expressways. Presented at the Transportation Research Board 94th Annual Meeting. No. 15-2433, Transportation Research Board of the National Academies, Washington, D.C., 2015.

3. Potts, I., J. Ringert and K. Bauer, et al. Relationship of lane width to saturation flow rate on urban and suburban signalized intersection approaches. In Transportation Research Record: Journal of the Transportation Research Board, No. 2027, Transportation Research Board of the National Academies, Washington, D.C., 2007, pp.45-51.

4. Transportation Research Board. Highway Capacity Manual. TRB. National Research Council, Washington, D.C., 2010 .

5. Leong, H. J. The Distribution and Trend of Free Speeds on Two Lane Two Way Rural Highways in New South Wales. Australian Road Research Board (ARRB) Conference, 4th, Melbourne, Vol. 4, No. 1, 1968.

6. Yagar, S., and M. Van Aerde. Geometric and environmental effects on speeds of 2-lane highways. Transportation Research Part A: General, Vol.17, No.4, 1983, pp.315-325.

7. Figueroa, M., A., and A. Tarko. Speed factors on two-lane rural highways in free-flow conditions. Transportation Research Record: Journal of the Transportation Research Board, No. 1912, Transportation Research Board of the National Academies, Washington, D.C., 2005, pp. 39-46.

8. BAI, X., S. ZENG, and Y. DU, et al. The research of urban expressway free-flow velocity. Traffic \& Transportation, Vol.2, No.9, 2006 (In Chinese).

9. Laval, J, A. Hysteresis in traffic flow revisited: An improved measurement method. Transportation Research Part B: Methodology.Vol.45, No.2, 2011, pp.385-391. 